\title{
Nailing the Situational Leadership Theory by Synthesizing the Culture and Nature of Principals' Leadership and Roles in School
}

\author{
Krizzette Joy Cuaresma-Escobar \\ Cagayan State University, Andrews Campus, Philippines
}

\begin{abstract}
Leadership circulates via the networks of positions that make up organizations. People's resources serve as the medium and currency of leadership. This research focuses on integrating the culture and nature of the principals' leaders and responsibilities in the school while adhering to the situational leadership theory. The descriptive survey technique of research was utilized in this study. Findings show, that principals must also properly manage opportunities. The principal may be an educational expert continually by creatively scientifically integrating ideas, materials, and human resources to meet the demands of time while also being supportive of his subordinates' accomplishments. When working habits and interpersonal connections are shown in the workplace, effectivity occurs.
\end{abstract}

Keywords---leadership, political, power, principal, situational leader theory.

\section{Introduction}

The principal is the school's highest-ranking administrator. Principals generally report directly to the school superintendent, although in school districts, they may report to the superintendent's designee, usually an associate superintendent. Headmasters have much of the same duties as principals, but they may also participate in extracurricular activities. In certain school systems, the superintendent and principal are the same people (Addi-Raccah \& Ainhoren, 2009; Turhan, 2010). School leaders include principals, headmasters, and those who are in charge of the general running of a school. In an era of shared decisionmaking and site-based administration, the phrase school leader may also apply to other school administrators and leaders, such as assistant principals, lead teachers, and others who engage in school leadership activities.

Linguistics and Culture Review (C) 2021.

Corresponding author: Cuaresma-Escobar, K. J.; Email: krizzeluke981@yahoo.com

Manuscript submitted: 09 June 2021, Manuscript revised: 27 Sept 2021, Accepted for publication: 15 Oct 2021 
A role is a person's action or function in an activity, while a leadership style is a method and approach to giving guidance, executing goals, and inspiring others. A principal has his or her unique method of juggling many responsibilities in the school. Whether he or she is effective to everyone relies on how he or she integrates/projects in school. Some principals quit teaching because of the numerous demands that their management duties put on their time. Their responsibilities include resource supplier, instructional leader, communicator, and visible presence. They also involve the production of board reports, political leadership in the local neighborhood, and reacting to a variety of internal and external pressure groups' requests. 3 Successful leaders are self-aware. They are aware of their capabilities, values, and best practices. According to Drucker (1999), leaders must first learn to govern themselves before they can lead others. According to leading researchers, the public school environment is so complicated that administrators must recognize that there are no one-size-fits-all solutions for implementing school reform. 4 Principals' expectations may be compared to the skill of learning music as they encounter different changes. As students acquire a better understanding of the entire piece, they move their focus to another. And these things will differ depending on how they manage to keep the school moving and productive as they typically believe. And people's expectations of what they can provide are enormous (Sims Jr et al., 2009; Piaw et al., 2014). Successful principals achieve goal consensus by collaborating with employees to create a common vision of what the school might become since there are parts of their duties that they may or may not overlook, which has an impact on the school. The principals are the school's gatekeepers. They can influence and mold positions as well as offer leadership. Adhering to the situational leadership theory would entail collaborative work among the stakeholders of the school to attain the vision, mission, goals, and objectives of the school. As a result, the study's primary goal is to synthesize the culture and nature of principals' leadership roles (Fernandez \& Vecchio, 1997; House \& Howell, 1992).

\section{Statement of the problem}

- What are the characteristics of the principals?

- age

- gender

- civil status

- government education passed

- highest educational attainment

- length of service

- How do the respondents perceive the role of the principal?

- Subject coordinators

- resource provider,

- instructional leader, communicator, and visible presence

- preparation of board reports,

- political leadership in the immediate community, and

- responding to a multiplicity of demands by internal and external pressure groups?

- Teachers

- resource provider, 
- instructional leader, communicator, and visible presence

- preparation of board reports

- political leadership in the immediate community, and

- responding to a multiplicity of demands by internal and external pressure groups?

\section{Theoretical framework}

This research is based on the responsibilities and leadership styles of public school administrators, and it will serve as the foundation for a suggested management improvement program. This research was based on certain carefully selected ideas proposed by Paul Hershey and Kenneth Blanchard. Situational leadership theory argues that various styles of leadership are better suited to certain situations and not others. They established four distinct leadership styles by assigning a high or low level of care to a leader's concern for both the job at hand and the individuals involved (Balyer et al., 2015; Villa \& Tulod, 2021). According to situational theory, a leader's style should vary depending on how willing and capable the individual is. Depending on the circumstance, principals must use a variety of leadership styles. It would differ from one individual to the next depending on their positions' competency and leadership styles.

\section{Related literature}

The essence of the principal's leadership and responsibilities in school is to blend in, adapt, and gain approval. He is motivated to come up with effective ways of enforcing regulations. As asserted by Alimo-Metcalfe (1998), the social character of new principals' roles in schools is more pronounced, and leadership is a feature of social systems rather than individuals. Understanding that social groupings have a unique power linked to leadership that is different from individual influence may help to broaden understanding and enhance educational leadership practice. Affirmed by Bell (1997), looking back on principals' responsibilities in schools, they each have their plan for achieving success since they each have their accustomed attitude about how the strategy should be executed successfully.

Uttered by Clegg (1989), principals' responsibilities all include some kind of leadership, including instructional leadership, supervisory leadership, organizational leadership, administrative leadership, and team leadership. The behaviors relate to establishing the general concept and purpose of the school; leading the achievement of educational objectives at the school; creating a supportive school structure and environment; maintaining these circumstances over time; and working with teachers, other administrators, and employees. Leadership theories have evolved throughout time as the contexts in which they were examined have changed.

As declared by Douglas (1982), leaders who are always aware of organizational expectations and strive to fulfill them are more likely to be successful in winning staff loyalty while proposing change and during times of crisis. According to today's leadership and management experts, no one leadership style will be able to successfully address the challenges that emerge from a rapidly changing and 
technologically advanced environment. According to some experts, for educational leaders to successfully implement major school reforms, they must first completely understand their strengths and limits to find solutions inside the school organization or implement a school development plan.

\section{Methodology \\ Research method used}

This study will employ the descriptive survey method of research. Using the descriptive survey, this study will gather quantitative and qualitative data from the profile of the respondents about age, gender, civil status, educational background, and length of service (Thoyib et al., 2021; Ziyadin et al., 2018).

\section{Respondents of the study}

The population frame of the study will consist of 17 public elementary schools in Metro Manila. The respondents are 85 subject coordinators and 85 teachers.

\section{Sloven's formula}

To determine the sample size of the population. The formula in getting the Slovin's formula is:

$$
\begin{gathered}
\mathrm{n}=\mathrm{N} \\
1+\mathrm{Ne}^{2}
\end{gathered}
$$

\section{Sampling technique}

This study will be using the simple random sampling technique where we select a group of subjects (a sample) for study from a larger group (a population). Each individual is chosen entirely by chance and each member of the population has an equal chance of being included in the sample. Every possible sample of a given size has the same chance of selection. In this study, the researcher set the following criteria: the respondents must be working or teaching in the public elementary division.

\section{Instruments to be used}

This study will use a survey questionnaire based on cited roles and leadership styles made by Ann W. Hart and David A. Sousa which the researcher has prepared and observed as the main tools in gathering data. The questionnaire will be constructed by the researcher based on the statement of the problem. The instruments that will be used to collect the data will be covered in two parts. Part I. Respondents' Profile. This identified the needed information on the background of the respondents/principals such as name (optional), age, gender, civil status, highest educational attainment, and length of service. Part II. Assessment of the roles and leadership styles of the principals to be assessed by the subject coordinators and teachers (Fairhurst, 2005; Daniëls et al., 2019). The questions here aimed to assess how effective the roles and leadership styles of public elementary principals; basis of a proposed management enhancement program. 


\section{Validation of the instrument}

Validation was carried out with the assistance of chosen Education Professors and Administrators at CEU, as well as her advisor. The comments and recommendations of the aforementioned authorities will be taken into account while developing the final form of the questionnaire.

\section{Data gathering procedure}

To get a comprehensive result, the researcher will follow the data collection method outlined below. Observation and interviews will be conducted to enhance the researcher's belief in the study's conclusions. The researcher then developed a survey questionnaire based on the findings of the many relevant investigations (Culler, 1981; Derrida, 1984; Mutch, 2015). The questionnaires were the main method for gathering data for the research. Before the distribution of the question, the researcher will secure an approval letter from the Regional Director of National Capital Region (NCR) Elementary Division and the designated Schools Division Superintendent in each city. Finally, copies of the questionnaire will be distributed to the selected respondents for assessment which will be collected, tallied, and analyzed.

\section{Statistical treatment used}

The data will be subjected to statistical treatment to make the interpretation of the present study reliable. The data gathered from the accomplished questionnaires and checklists will be submitted and processed at Centro Escolar University for data analysis.

\section{Results and Discussions}

\section{Profile of the principals in selected public elementary schools in Metro Manila}

- Age. The age of the principals in selected public elementary schools in Metro Manila was presented. It shows that 41. 2 percent of the total 17 respondents belonged to the 51-60 age group; 35.3 percent belonged to the 61 and above age group; 17.6 percent belonged to the 41-50 age group and 5.9 percent to the 31-40 age group. It can be inferred that most of the principals' ages when they reached the position belonged to ages 50-60s.

- Gender. The frequency and percentage distribution of principals in selected elementary schools in Metro Manila according to Gender. Most of the respondents are female numbering 14 of the 17 respondents comprising 82.4 percent. Only 3 are male consisting of 17.6 percent. It may be said that most principals were female.

- Civil Status. There is 14 or 82.1 percent who are married; 2 or 11.8 percent who are single; 1 or 5.9 percent a widowed and none of the results are separated. This shows that most principals were married.

- Government Examinations Passed. It is significant to determine the government examinations that the principal undertook because this is one aspect that they have already acquired a standard in their position. It can 
be noted from table 4 that 11 or 64.7 percent had passed the civil service professional; 3 or 17.6 percent had passed their local board; 2 or 11.8 percent had passed the principalship test and 1 or 5.9 percent had passed the civil service sup-professional examinations. This shows that most principals undertook several examinations.

- Educational Attainment. This shows that 7 or 41.2 percent corresponds to the majority of the respondents already earned their Master's degree.

- Length of Service. This shows that 8 or 47.1 percent corresponds that the majority of the principals had rendered 26 and above the length of service. This shows that acquiring the position must have enough experience.

\section{Perception of the subject coordinators on the role of the principals}

- Resource Provider. The data from table 7 shows that the subject coordinators rated items on availability of resources with the highest mean perception about principals' role of 4.61. This was followed by items 1 and 3 with a mean perception of 4.67. On the other hand, manages school resources was rated with a mean perception of 4.62; followed by stimulating discussions about school plans with a mean perception of 4.61. Providing opportunities for joint projects having the lowest mean perception of 4.51. The standard deviation signifies heterogeneity, which implies that the subject coordinators gave high and low mean perceptions.

- Instructional leader, communicator, and visible presence. As shown in Table 8, the subject coordinators gave high ratings to implement tasks appropriately with a rated mean perception of 4.63; followed by items 1 and 2 with a rated mean of 4.59. On the other hand, practices open communication got a mean of 4.55; while providing resources to school programs got a rating of 4.54. In general, implementing tasks appropriately got the highest mean perception because as an instructional leader, you must have a clear vision of the task that you have to implement in school and also to your subordinates (Austin, 1975; Benford \& Hunt, 1992).

- Preparation of Board Reports. In table 9, the perception of subject coordinators under preparing a board reports revealed that being objective in implementing rules and policies had the highest mean perception of 4.75; followed by items 1 and 3 with a mean perception of 4.73. Focuses the discussions on the desired goals having a mean of 4.71 ; while ensuring school's welfare has a 4.65 mean perception. In terms of preparing board reports, being objective in implementing rules and policies, and also specific and managing meetings and developments are the biggest considerations.

- Political leadership in the immediate community. Table 10 presents the perception of the subject coordinators on the role of the principal as to political leadership in the community. As a result on the table, items 3 and 5 have the same rating with a mean perception of 4.58; knowledgeable in sharing the needs of the school and emphasize real action in relating school plan. Sharing decisions actively and collectively got a rating of 4.53; while the ability to create opportunities got a perception mean of 4.45 . The least emphasized was facilitating interpersonal relations with a mean of 4.41. Based on the results, it should be a practice of the principals to be knowledgeable on the needs of the school and take real actions on them. 
- Responding to a multiplicity of demands by internal and external pressure groups. The data in table 11 revealed that subject coordinators gave a high mean perception of 4.61; ensures that priorities are well set. Quick in producing solutions followed next with a mean perception of 4.58. On the other hand, presence is appropriate to tasks with a mean of 2.52; is fair and making decisions got a mean of 4.47; while manages pressures got a mean perception of 4.40. These findings implied that certain solutions must arrive at the fastest possible.

\section{Perception of the teachers on the role of the principals}

- Resource Provider. On table 12 presents the perception of teachers to principals on their role as a resource provider. Based on the results, sets the objective for change and innovation got the highest mean perception of 4.83; followed by manages school's resources with a mean perception of 4.77. Moreover, items 2 and 4 got the same mean perception of 4.71 ; stimulates discussions about school plan and provides opportunities for joint projects. Ensures a coordination role got the least score of 4.64. These results implied that principals must set an objective for change and innovation to create an atmosphere of improvement.

- Instructional leader, communicator, and visible presence. The data in table 13 shows item 1- ensures harmonization of the school policies got the highest mean perception of 4.82; the second most emphasized item was attending to school problems immediately with a rated mean of 4.77. Moreover, the third emphasized was practicing open communication with a score of 4.75; while implementing task appropriately having a result of 4.73 . The least emphasized score was 4.60; provides resources to school programs. These findings denoted that principals must inject harmonization of the school policies to create an atmosphere of unity and change. Goals must undoubtedly be set by the administration; otherwise, there can be no definition of success or progress. However, Derrida (1988), pointed out that the administrator's objectives are only tangentially linked to educational objectives for children. The administrator's priority is to keep his job. The organization's success in terms of continuity, development, and absence of instability is the second objective. Leadership flows via the networks of positions that make up organizations believed to Butler (2002), resources serve as the medium of leadership and the currency of leadership. The mechanisms that create patterns of interaction and the meanings that other participants attach to organizational events are shaped by leadership.

- Preparation of Board Reports. Table 14 reveals that managing meetings and developments got the highest mean perception of 4.76; followed by ensuring the school's welfare of 4.73. Both items 1 and 4 got the same result of 4.71 ; are specific in his/her objectives and are objective in implementing rules and policies. The least emphasized was item 2 with a mean perception of 4.69; focuses the discussions on the desired goals. The data were evident that principals must have big considerations on managing meetings and developments to have a smooth flow on topics that were discussed. Based on situational leadership theory, the duties and functions of the leader/senior management approach the concept of leadership in two distinct ways. First, it stresses the need of top management to exercise 
change and direction leadership, i.e. defining the direction of changes and advancements. Second, top executives must support changes started in other parts of the company owing to their seniority in the organization to give an initiative weight.

- Political leadership in the immediate community. In table 15 the perception of the teachers on the role of the principal as to political leadership in the community revealed that principals must share decisions actively and collectively (4.62); while knowledgeable in sharing the needs of the school got a mean perception of 4.59. Moreover, emphasizes real action in relating school plan got a mean score of 4.54 ; followed by 4.49 , ability to create opportunities and facilitates interpersonal relations with a mean score of 4.42. These data denoted that as principals engaged in political leadership in the community; they should be able to share decisions actively and collectively to have a bigger chance of participating in the betterment of the school plans and the community.

- Responding to a multiplicity of demands by internal and external pressure groups. As shown in table 16, ensures that priorities are well set got the highest mean perception of 4.59; followed by is fair in making decisions with a mean score of 4.55. Presence is appropriate to tasks got a mean perception of 4.48; quick in producing solutions having a mean perception of 4.45 and item 3, manages pressures having the least mean perception of 4.44. As revealed in the results, principals should give importance to ensuring their priorities have a better direction on school's demands/plans. Believed by Aristotle (1991), power, according to the theory of situational leadership, is the capacity to convince others to do something they don't want to do. Although power does not have to be exercised in the form of a command, evidence of its existence requires the shattering of another's will. Principals have very limited power. For example, they can only compel all teachers to do something they don't want to do under extraordinary circumstances. Bell (1997), propounded that authority may be defined in a variety of ways. It is claimed that a scientific text has authority. One indicates that its authority is genuine. A job or position may also provide you with power.

\section{Comparison between the perception of the subject coordinators and teachers as regards to the principals' roles}

Table 17 presents the comparison between the perception of the subject coordinators and teachers on the roles of the principals. The data shows that there is no significant difference in the perception as evident in the results. This indicates that the perception of the subject coordinators and teachers as regards the leadership styles based on results revealed that principals have several leadership styles with a percentage of 61.2 ; democratic/participative having a percentage of 10.0. However, both systematic and situational have the same percentage of 8.2. Autocratic/Bureaucratic had a percentage of 7.1 , and the least emphasized was transactional and transformational having 9 or 5.3 mean perception (Batstone et al., 1976; Bryman, 1992).

Based on the results, it can be inferred that principally acquires more than one leadership style. Asserted by Culler (2000), a leadership strategy is a planned 
pattern of conduct aimed at gaining followers' participation in achieving corporate objectives. With this realization, some leaders seem to have a constant approach that is more than just a reflection of their psychological makeup throughout time.

\section{Conclusion}

The researcher made the following conclusions based on the summary of findings:

- As shown in the summary of findings, subject coordinators' ratings of the principals' role as resource providers in providing opportunities for joint projects were relatively low when compared to other items. It is self-evident that principals must also properly manage opportunities.

- According to the findings, subject coordinators' perceptions of their ability to create opportunities under item-political leadership in the community are only slightly low or agree only.

\section{Recommendations}

In consideration of the conclusions stated, it is recommended that the principals

- It is recommended that public elementary school administrators implement an innovative program that responds to the current demand for integrating skilled people into the educational system.

- Both administrators and teachers see educational leadership as dynamic and creative when it comes to addressing educational problems. As a result, the principal should continue to be educational experts by creatively scientifically integrating ideas, materials, and human resources to meet time demands and develop the ability to encourage their teachers to explore new ideas, programs, and strategies to improve educational quality.

\section{References}

Addi-Raccah, A., \& Ainhoren, R. (2009). School governance and teachers' attitudes to parents' involvement in schools. Teaching and Teacher Education, 25(6), 805-813. https://doi.org/10.1016/j.tate.2009.01.006

Alimo-Metcalfe, B. (1998). Effective leadership. London: Local Government Management Board.

Aristotle, G. A. (1991). Aristotle on rhetoric a theory of civic discourse.

Austin, J. L. (1975). How to do things with words. Oxford university press.

Balyer, A., Karatas, H., \& Alci, B. (2015). School principals' roles in establishing collaborative professional learning communities at schools. Procedia-Social and Behavioral Sciences, 197, https://doi.org/10.1016/j.sbspro.2015.07.387

Batstone, E., Brannen, P., Fatchett, D., \& White, P. (1976). The Worker Directors. Bell, C. M. (1997). Preface to Ritual: Dimensions and Perspectives.

Benford, R. D., \& Hunt, S. A. (1992). Dramaturgy and social movements: The social construction and communication of power. Sociological inquiry, 62(1), 36-55.

Bryman, A. (1992). Charisma and leadership in organizations.

Butler, J. (2002). Gender trouble. routledge. 
Clegg, S. R. (1989). Frameworks of power. Sage.

Culler, J. (1981). Convention and meaning: Derrida and Austin. New Literary History, 13(1), 15-30.

Culler, J. (2000). Philosophy and literature: The fortunes of the performative. Poetics Today, 21(3), 503-519.

Daniëls, E., Hondeghem, A., \& Dochy, F. (2019). A review on leadership and leadership development in educational settings. Educational research review, 27, 110-125. https://doi.org/10.1016/j.edurev.2019.02.003

Derrida, J. (1984). Deconstruction and the Other. Dialogues with contemporary continental thinkers, 105-126.

Derrida, J. (1988). Limited inc. Northwestern University Press.

Douglas, L. D. (1982). A comparison of life experiences and leader behaviors between male and female superintendents (Doctoral dissertation, Seattle University).

Drucker, P. F. (1999). The new pluralism. Leader to leader, 1999(14), 18-23.

Fairhurst, G. T. (2005). Reframing the art of framing: Problems and prospects for leadership. Leadership, 1(2), 165-185.

Fernandez, C. F., \& Vecchio, R. P. (1997). Situational leadership theory revisited: A test of an across-jobs perspective. The Leadership Quarterly, 8(1), 67-84. https: / / doi.org/10.1016/S1048-9843(97)90031-X

House, R. J., \& Howell, J. M. (1992). Personality and charismatic leadership. The Leadership Quarterly, 3(2), 81-108. https://doi.org/10.1016/10489843(92)90028-E

Mutch, C. (2015). Leadership in times of crisis: Dispositional, relational and contextual factors influencing school principals' actions. International Journal of Disaster Risk Reduction, 14, 186-194. https://doi.org/10.1016/j.ijdrr.2015.06.005

Piaw, C. Y., Hee, T. F., Ismail, N. R., \& Ying, L. H. (2014). Factors of leadership skills of secondary school principals. Procedia-Social and Behavioral Sciences, 116, 5125-5129. https://doi.org/10.1016/j.sbspro.2014.01.1085

Sims Jr, H. P., Faraj, S., \& Yun, S. (2009). When should a leader be directive or empowering? How to develop your own situational theory of leadership. Business Horizons, 52(2), 149-158. https://doi.org/10.1016/j.bushor.2008.10.002

Thoyib, M., Widodo, W., Rohati, R., Mulyadi, E., \& Sutarman, S. (2021). The relationship of community leaders and social cultural environment with community participation in management of COVID-19 in Tangerang City. Linguistics and Culture Review, 5(S1), 1009-1019. https://doi.org/ 10.37028/lingcure.v5nS1.1486

Turhan, M. (2010). Social justice leadership: Implications for roles and responsibilities of school administrators. Procedia-Social and Behavioral Sciences, 9, 1357-1361. https://doi.org/10.1016/j.sbspro.2010.12.334

Villa, F. T., \& Tulod, R. C. (2021). Correlating instructional leadership practices of school administrators with teachers competencies. Linguistics and Culture Review, 5(S1), 83-99. https://doi.org/10.37028/lingcure.v5nS1.1318

Ziyadin, S., Shash, N., Kenzhebekova, D., Yessenova, G., \& Tlemissov, U. (2018). Data on the role of leadership in developing expertise in teaching in developing country. Data in brief, 18, 1127-1133. https: / /doi.org/10.1016/j.dib.2018.03.137 